\title{
Comparison of Povidone-lodine and Gentamicin Soak as Scleral Buckle Infection Prophylaxis
}

\author{
Xihui Lin \\ Brian Le \\ Patrick Lee (1D \\ Gary W Abrams \\ Mark Juzych \\ Ashok Kumar
}

Department of Ophthalmology, Kresge Eye Institute, Detroit, MI, 4820I, USA
Correspondence: Xihui Lin Department of Ophthalmology, Kresge Eye Institute, 47I 4 St. Antoine Street, Detroit, MI, 4820I, USA

Email xihui.lin@wayne.edu
Objective: To determine the best method of antimicrobial prophylaxis against implanted material-associated infections in the setting of scleral buckle surgery.

Design: Experimental study.

Participants: Scleral buckle elements were soaked in either gram-positive or polymicrobial broth, while control buckle elements were soaked in PBS only.

Methods: Solid silicone and sponge scleral buckle elements were inoculated with common pathogens of the ocular surface, and then soaked in either $1 \%$ or $5 \%$ povidone-iodine, $1 \mathrm{mg} /$ $\mathrm{mL}$ gentamicin solution, or sterile saline for $1,5,10$, or 15 minutes. Bacteria were then isolated from the buckle elements and cultured for 24 hours.

Results: In all gram-positive bacterial conditions, gentamicin solution decreased the bacterial load from 451,666.67 colony-forming units (CFU)/mL to $171,611.11 \mathrm{CFU} / \mathrm{mL}$ $(\mathrm{p}=0.0004)$. The fractional bacterial survival after soaking in gentamicin was higher for the silicone sponge than band ( 0.357 vs $0.079, \mathrm{p}=0.038)$. Both $1 \%$ and $5 \%$ povidone-iodine were able to completely eradicate all gram-positive bacteria of both buckle elements. Only $5 \%$ povidone-iodine was able to completely sterilize all microbes on the buckle after soaking in a polymicrobial solution consisting of gram-positive, gram-negative bacteria, and fungi.

Conclusion: Povidone-iodine solution was significantly more effective at bacterial eradication compared to gentamicin solution. For all scleral buckle procedures, we recommend soaking the buckle element in $2-3 \%$ povidone-iodine solution before placement and rinsing the ocular surface with the same solution after placement.

Keywords: gentamicin, povidone-iodine, sterilization

\section{Introduction}

Surgeries requiring implanted materials have an increased rate of infection. ${ }^{1-3}$ This is thought to be due to alterations in host defense mechanisms, such as functional changes in the bactericidal activity of polymorphonuclear leukocytes accumulating around the foreign body as well as biofilm production. ${ }^{4}$ The rate of infection associated with an implanted scleral buckle element is estimated to be from $0.5 \%$ to $5.6 \%{ }^{5}$ It was shown that pre-placement soaking of episcleral buckle elements in antibiotic solution for 30 minutes significantly decreased the rate of buckle infection. ${ }^{6}$ Gentamicin at $1 \mathrm{mg} / \mathrm{mL}$ is a commonly used solution for infection prophylaxis due to its low cost and relative tolerability on the ocular surface.

In contrast, the efficacy of 5\% Povidone-iodine solution for pre-surgical ocular surface sterilization was demonstrated in 1984 and continues to be the ocular surface sterilization solution of choice for many ophthalmic surgeries today. ${ }^{7}$ Additionally, $0.25 \%$ povidone-iodine solution as an ocular surface wash after the 
placement of scleral buckles has been shown to have higher sterilization rate compared to saline wash. ${ }^{8}$ Anecdotally, some surgeons have used a dilute solution of povidone-iodine to soak the buckle element prior to placement. To date, no studies have compared the two approaches in terms of antimicrobial efficacy. In addition, to the best of our knowledge, no studies have addressed the amount of time surgeons should soak the buckle components prior to placement. The goal of this study is to compare the efficacy of different concentrations of povidone-iodine against gentamicin solutions, establish a guideline of what solution to use and how long to soak the components.

\section{Materials and Methods}

The two types of scleral buckle elements selected for the study were the $3.5 \mathrm{~mm} \times 0.75 \mathrm{~mm} 41$-style solid silicone band (band) and $3 \mathrm{~mm} \mathrm{X} 5 \mathrm{~mm}$ oval 506-style soft silicone sponge (sponge). Both the band and the sponge were cut into 20 equal pieces. Each segment of the sponge and band was approximately $4 \mathrm{~mm}$ and $6 \mathrm{~mm}$, respectively. For each experiment, two equal pieces of the band or sponge were simultaneously dipped into a bacterial broth for less than 5 seconds (see below for preparation). One piece was used as the positive control, and the other piece was dipped into the antimicrobial solution for the same amount of time. Both pieces of the buckle element were rinsed 3 times with $2 \mathrm{~mL}$ of phosphate-buffered saline (PBS). Each element was then placed into a sterile microcentrifuge tube with $250 \mu \mathrm{L}$ of PBS. After spinning the tube for 15 seconds on a vortex mixer, the PBS solution was serially diluted twice with equal volumes of PBS. All 3 samples (original undiluted and the 2 serially diluted) were plated onto culture plates and incubated at 37 degrees Celsius for 24 hours. Colony-forming units (CFU) were counted on the culture plates while adjusting for the serial dilutions. Initial experiments showed that the sponge was more difficult than the band to sterilize, so subsequent experiments were done with the sponge only.

Bacterial broth was prepared by culturing the desired bacteria overnight at 37 degrees Celsius. Initial experiments comparing the differences between bands and sponges, as well as duration of the antibiotic soak, were done using Staphylococcus aureus. Comparative studies between different concentrations of povidone-iodine and gentamicin were performed using a polymicrobial broth containing Staphylococcus aureus, Staphylococcus epidermidis, Pseudomonas aeruginosa, and Candida albicans.
$1 \%$ and $5 \%$ Povidone-iodine solutions were prepared by diluting $10 \%$ povidone-iodine solution with sterile normal saline. $1 \mathrm{mg} / \mathrm{mL}$ gentamicin solution was prepared by dissolving gentamicin powder in sterile normal saline. Both were prepared under sterile conditions under a hood.

This study was conducted in accordance with the Declaration of Helsinki. Ethical approval for this study was waived by the Wayne State University Institutional Review Board since no human or animal subjects were involved in the study.

\section{Results}

\section{Effect of Gentamicin on Soft Silicone Sponges versus Solid Silicone Bands}

Overall, $1 \mathrm{mg} / \mathrm{mL}$ of gentamicin solution decreased the microbial load by $62.00 \%$ from $451,666.67 \mathrm{CFU} / \mathrm{mL}$ to 171,611.11 CFU/mL ( $\mathrm{p}=0.0004)$. The initial experiments to determine the amount of bacteria inoculated onto the silicone sponge, compared to the silicone band did not find a significant difference between the two $(215,333.33 \mathrm{CFU} /$ $\mathrm{mL}$ vs $450,000.00 \mathrm{CFU} / \mathrm{mL}$ respectively, $\mathrm{p}=0.10$ ). However, the gentamicin solution was less efficacious at decreasing $\mathrm{CFU}$ on the silicone sponge compared to silicone band, with $64.3 \%$ compared to $92.1 \%$ decrease in microbial load, respectively $(\mathrm{p}=0.0038)$. No significant differences in $\mathrm{CFU}$ were found following soaking the buckles in the gentamicin solution for 1 minute, 5 minutes, 10 minutes or 15 minutes ( $>0.44$ ). Representative images of gentamicin-treated culture plates and positive-control plates are shown in Figure 1.

\section{Povidone-lodine Solution is Effective Against Gram-Positive Microbes}

Both $1 \%$ and $5 \%$ povidone-iodine solutions completely killed all gram-positive microbes regardless of sponge, band, or the duration of soaking. An additional condition was created in which the inoculated buckle component was dipped in the povidone-iodine solution and immediately taken out. Both the $1 \%$ and $5 \%$ povidone-iodine were able to sterilize all gram-positive microbes, even with a soak time of less than 5 seconds. An example is shown in Figure 2.

\section{5\% Povidone-lodine Solution is Effective Against Pseudomonas aeruginosa}

In sponges inoculated in polymicrobial solutions (including Pseudomonas aeruginosa), the initial microbial load was 

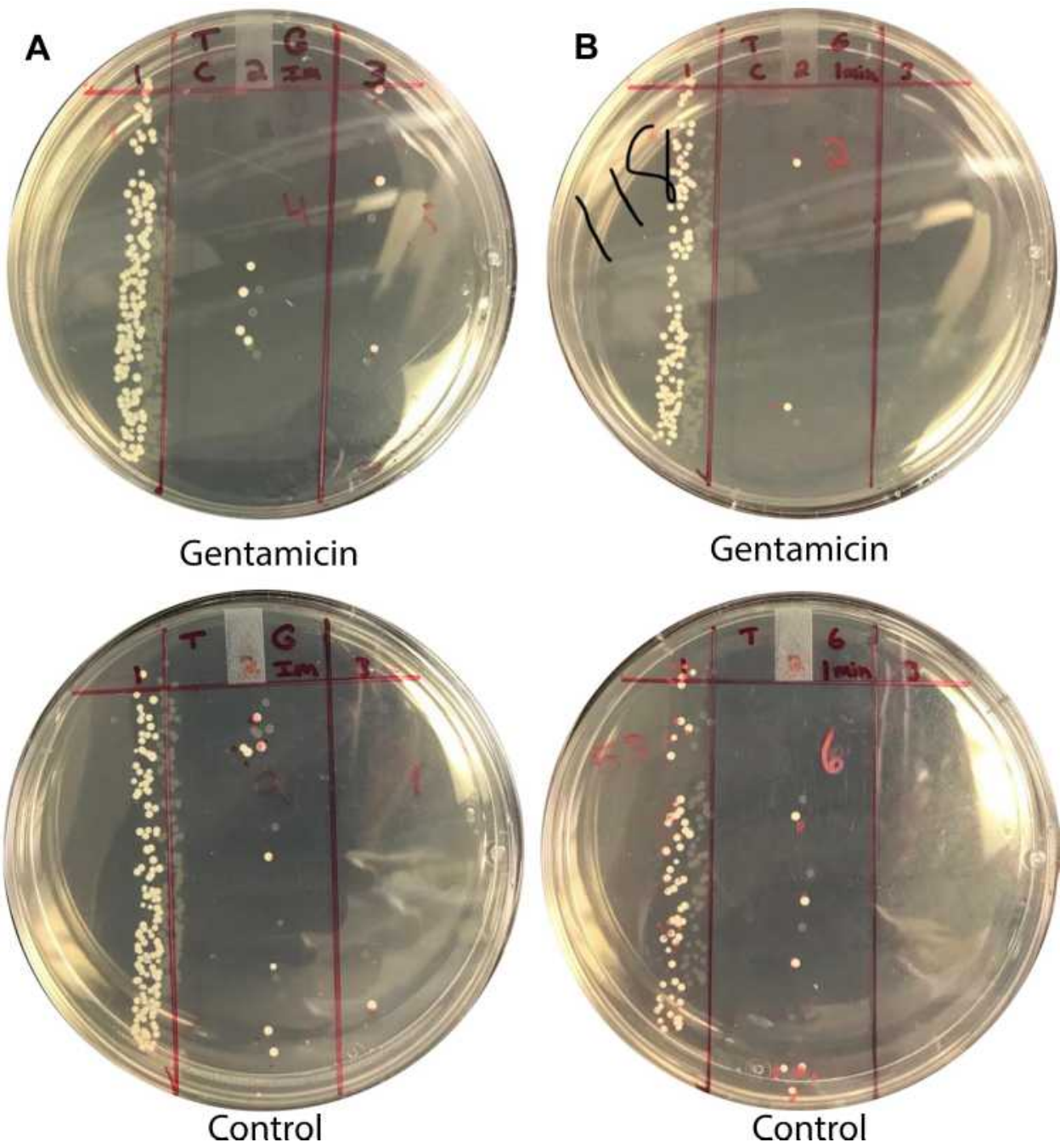

Figure I Gentamicin Soak Decreases S. aureus Bacterial Load on Silicone Sponges. Silicon sponges inoculated with S. aureus broth were dipped into I mg/mL gentamicin solution or control solution for a duration of I second $(\mathbf{A})$ or I minute (B). The left column on each plate represents undiluted sample. The middle and right column represent serially diluted samples. Fewer colonies were identified in sponges soaked with gentamicin relative to control, at all soaking durations.

much higher compared to gram-positive-only inoculated sponges. The final culture after soaking in the polymicrobial solution consisted almost entirely of pseudomonas due to the aggressive growth property of the microbe. In the polymicrobial-inoculated sponges, both the gentamicin solution and $1 \%$ povidone-iodine solution have decreased antimicrobial efficacy relative to the gram-positive only conditions, with $33.33 \%$ and $97.62 \%$ bacteria decrease, respectively. However, 5\% povidone-iodine with less than 5 seconds soak time was still able to sterilize pseudomonas-inoculated sponges (Figure 3).

\section{Conclusions}

This series of experiments conclusively demonstrated that povidone-iodine was a stronger antimicrobial agent against several common microorganisms compared to $1 \mathrm{mg} / \mathrm{mL}$ gentamicin. The difference is so profound that a meaningful statistical test could not be performed since the final $\mathrm{CFU} / \mathrm{mL}$ was zero for the majority of the tests utilizing povidone-iodine. A Chi-squared test using categories of sterilized vs not sterilized also would not add significantly to the study given that none of the gentamicin experiments achieved complete sterilization while all but one of the povidone-iodine experiments did.

The difference in inoculation load and gentamicin effectiveness between the band and the sponge was not unexpected. The porous nature of the sponge may have "shielded" some bacteria embedded within the sponge from the more concentrated gentamicin solution at the surface. However, the ability of the povidone-iodine to sterilize the sponge likely represents the stronger antimicrobial activity rather than purely better penetration. 

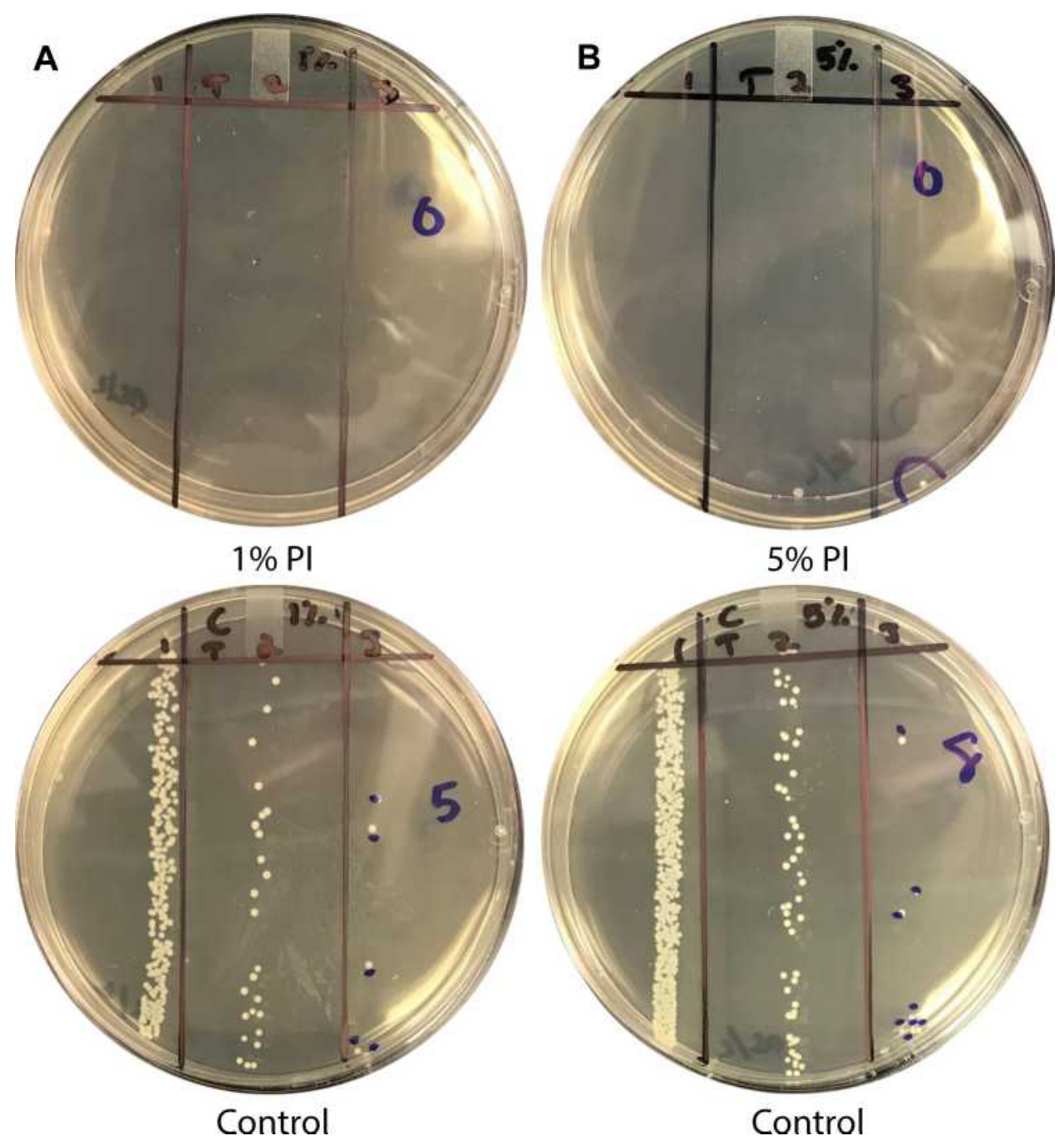

Figure 2 Povidone-lodine Soak Decreases S. aureus Bacterial Load on Silicone Sponges. Silicon sponges inoculated with S. aureus broth were dipped into I\% Povidonelodine (PI) (A) or 5\% Povidone-lodine (B) solution or control solution for a duration of I second. The left column on each plate represents undiluted sample. The middle and right column represent serially diluted samples. No colonies were identified in sponges soaked with Povidone-lodine relative to control.

The scleral buckle is presumed to be sterile when packaged; however, there is risk of contamination of the buckle after it is removed from the packaging. The buckle will be handled by surgical instruments and/or gloved fingers and will be in contact with the ocular surface. Contamination of the sterile surgical instruments from airborne pathogens is not uncommon, with reported rates of over $20 \%$ when surgical trays were opened for 2 hours. ${ }^{9-13}$ Additionally, if the instruments and/or fingers that handle the buckle elements have been in contact with the ocular surface or surgical wound, there is increased risk of contamination from ocular surface or adnexal flora. ${ }^{14,15}$ Prior studies have shown a reduced incidence of infection or extrusion of scleral buckles following soaking the elements in penicillin, gentamicin and chloromycetin, so due to the risk of contamination, we typically soak the buckle element in an antimicrobial solution prior to implantation and wash the sub-tenon space adjacent to the buckle with the same antimicrobial solution prior to conjunctival closure. ${ }^{6,16}$ Our previous preference was $1 \mathrm{mg} / \mathrm{mL}$ gentamicin solution for both soaking the buckle and washing the buckle and tenons space postplacement. Although there may be a difference in bacteria susceptibility, it is still unlikely to achieve full sterilization at the same rate as povidone-iodine, especially against gram negative pathogens.

In our study, 5\% povidone-iodine solution had increased antimicrobial activity compared to $1 \%$ solution, even with under 5 seconds of soak time. Previous in vitro and animal studies have suggested that povidone-iodine 


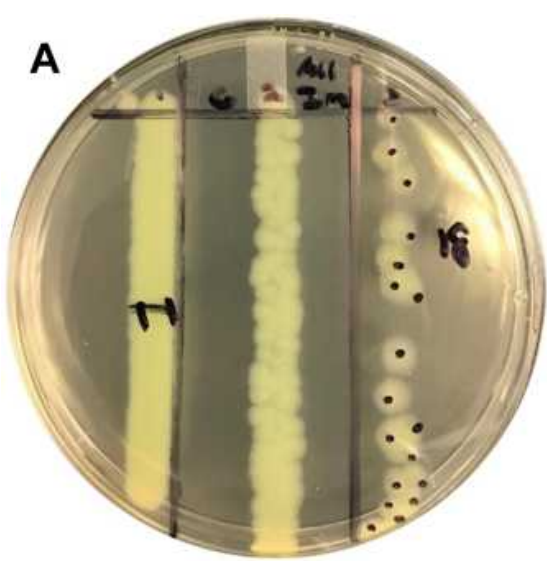

Gentamicin

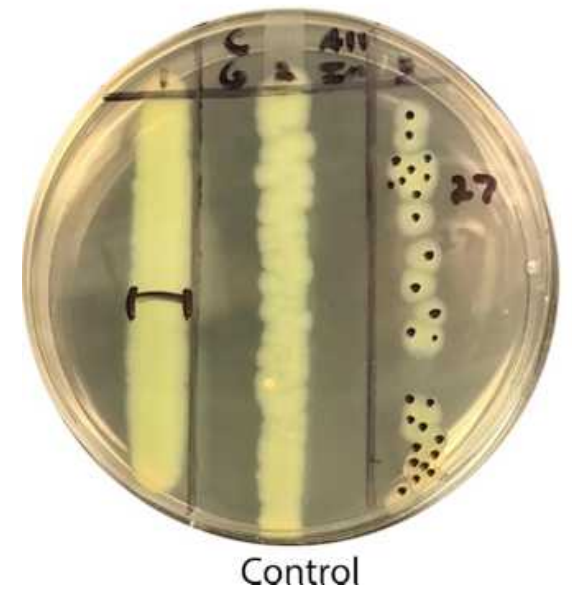

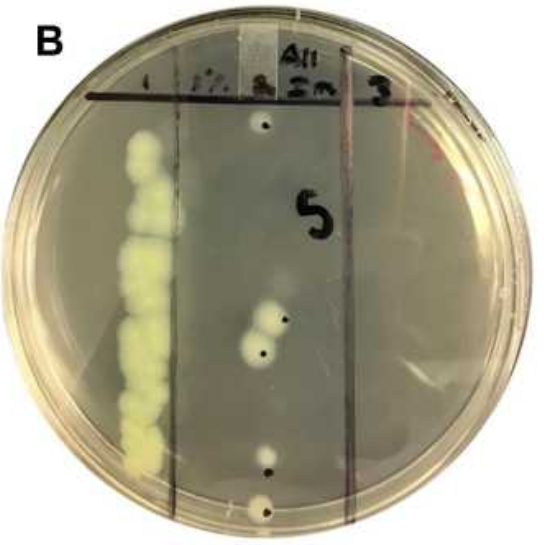

$1 \% \mathrm{PI}$

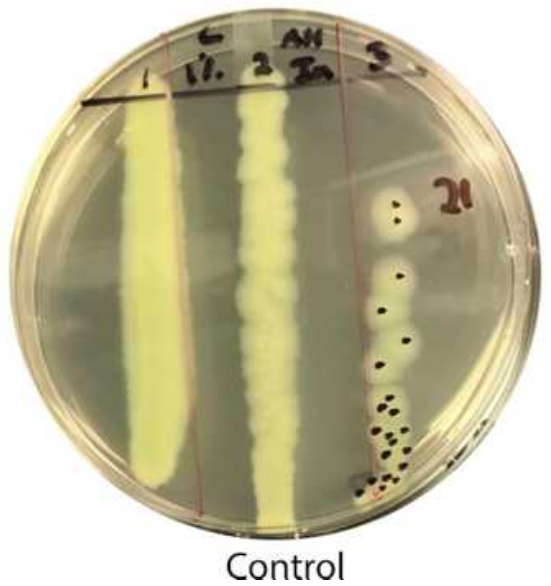

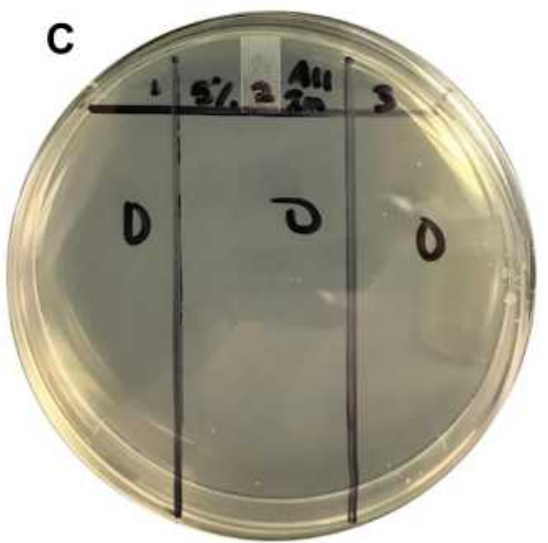

$5 \% \mathrm{PI}$

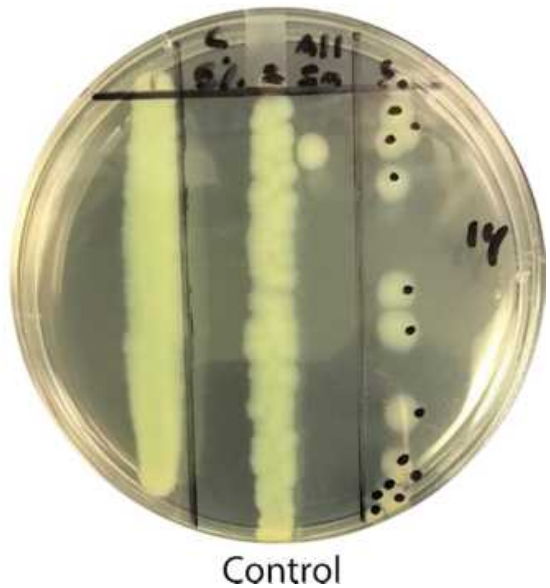

Figure 3 5\% Povidone-lodine Soak Eliminates P. aeruginosa Bacterial Load on Silicone Sponges. Silicone sponges inoculated with $P$. aeruginosa broth were dipped into I mg/ $\mathrm{mL}$ gentamicin (A), I\% Povidone-lodine (PI) (B) solution, or $5 \%$ Povidone-lodine (C) solution for a duration of I second. The left column on each plate represents undiluted sample. The middle and right column represent serially diluted samples.

solution is paradoxically more effective at lower, more dilute concentrations. ${ }^{17,18}$ This was hypothesized to be because in higher concentration solutions, polyvinylpyrrolidone aggregates trap the active antimicrobial free iodine, preventing them from binding microbial membranes. However further in vivo studies in patients showed that $5 \%$ solution is more effective in decreasing conjunctival flora, particularly with higher microbial densities. This was thought to be due to the fact that though the $1 \%$ solution has higher bactericidal activity, the "reservoir" of free iodine may be exhausted by a higher microbial density. ${ }^{19}$ It is possible that our results demonstrating the superior efficacy of 5\% solution may not hold true for lower microbial loads.

Since this study, our practice has changed to using $2-3 \%$ povidone-iodine solution for both the preplacement soaking and post-placement rinsing without postoperative discomfort or complications attributable to povidone-iodine. Although 5\% povidone-iodine has been shown to be safe on the ocular surface, it has been documented to cause irritation of the conjunctiva and/or skin in a dose-dependent manner in some patients, though this is uncommon. ${ }^{7,20-22}$ Povidone-Iodine also retards wound healing in rabbit models, ${ }^{23}$ though no cytotoxic effects on the cornea were observed in patients undergoing cataract surgery. ${ }^{24}$ We speculate that $2-3 \%$ povidone-iodine may be a good compromise between the more effective $5 \%$ solution and safer $1 \%$ solution. Our study is unable to identify whether soaking of buckle elements in povidoneiodine or gentamicin alters the rate of contamination by ocular flora after buckle placement. It is possible that the silicone sponges absorb some gentamicin and povidoneiodine and slowly release over time, but this is likely limited in the solid silicone elements. Overall, given the significant difference in bactericidal potency between gentamicin and povidone-iodine solutions, it can be presumed that the final wash with povidone-iodine would better sterilize the ocular surface adjacent to the buckle. 
Another limitation of this study is that the microbial load used in these experiments exceeded the microbial load on a prepped ocular surface. However, this "supraphysiologic" experimental microbial load is useful to differentiate the effectiveness between gentamicin and povidone-iodine. The conclusions of this study likely would not have been apparent at lower microbial loads. For example, low inoculant loads may not have revealed the difference in final bacteria growth between silicone bands and sponges after treatment with gentamicin soak.

Although gentamicin is not representative of all antibiotics, we believe the findings in this study can be generalized to other antibiotic solutions. Antibiotics with strong grampositive effects such as penicillin may perform better than gentamicin in the gram-positive arms of this study but are still unlikely to completely sterilize the buckle elements with short duration soak. The most resistant organisms were in the gram-negative experiments and it is unlikely any antibiotic solution can perform significantly better than gentamicin to the degree of complete sterilization.

In conclusion, the povidone-iodine solutions at $1 \%$ and $5 \%$ were more effective at sterilizing contaminated scleral buckle elements compared to gentamicin solution for common gram positive and gram-negative organisms of the ocular surface. Since the study, we have changed our scleral buckle soaking and rinsing solutions from gentamicin to $2-3 \%$ povidone-iodine. We soak the buckle elements for five minutes prior to buckle placement.

\section{Author Contributions}

All authors made substantial contributions to conception and design, acquisition of data, or analysis and interpretation of data; took part in drafting the article or revising it critically for important intellectual content; agreed to submit to the current journal; gave final approval of the version to be published; and agree to be accountable for all aspects of the work.

\section{Funding}

This work was supported by the National Eye Institute [F30-EY025923] (to Patrick SY Lee); Research to Prevent Blindness [P30-EY04068] (Non-restricted grant to the Department of Ophthalmology, Visual and Anatomical Sciences).

\section{Disclosure}

The authors declare that there are no conflicts of interest.

\section{References}

1. Elek SD, Conen PE. The virulence of Staphylococcus pyogenes for man; a study of the problems of wound infection. Br J Exp Pathol. 1957;38:573-586.

2. James RC, Macleod CJ. Induction of staphylococcal infections in mice with small inocula introduced on sutures. Br J Exp Pathol. 1961;42:266-277.

3. Noble WC. The production of subcutaneous staphylococcal skin lesions in mice. Br J Exp Pathol. 1965;46:254-262.

4. Zimmerli W, Waldvogel FA, Vaudaux P, Nydegger UE. Pathogenesis of foreign body infection: description and characteristics of an animal model. J Infect Dis. 1982;146:487-497. doi:10.1093/infdis/146.4.487

5. Chhablani J, Nayak S, Jindal A, et al. Scleral buckle infections: microbiological spectrum and antimicrobial susceptibility. $J$ Ophthalmic Inflamm Infect. 2013;3:67. doi:10.1186/1869-5760-3-67

6. Arribas NP, Olk RJ, Schertzer M, et al. Preoperative antibiotic soaking of silicone sponges. Does it make a difference? Ophthalmology. 1984;91:1684-1689. doi:10.1016/S0161-6420(84)34105-7

7. Apt L, Isenberg S, Yoshimori R, Paez JH. Chemical preparation of the eye in ophthalmic surgery. III. Effect of povidone-iodine on the conjunctiva. Arch Ophthalmol. 1984;102:728-729. doi:10.1001/ archopht.1984.01040030584025

8. Shimada H, Nakashizuka H, Hattori T, et al. Prophylaxis for acute scleral buckle infection using $0.25 \%$ povidone-iodine ocular surface irrigation during surgery. Int Ophthalmol. 2014;34(2):211-216. doi:10.1007/s10792-013-9816-5

9. Dalstrom DJ, Venkatarayappa I, Manternach AL, Palcic MS, Heyse BA, Prayson MJ. Time-dependent contamination of opened sterile operating-room trays. J Bone Joint Surg Am. 2008;90 (5):1022-1025. doi:10.2106/JBJS.G.00689

10. Widmer AF, Houston A, Bollinger E, Wenzel RP. A new standard for sterility testing for autoclaved surgical trays. J Hosp Infect. 1992;21:253-260. doi:10.1016/0195-6701(92)90136-A

11. Robinson AH, Drew S, Anderson J, Bentley G, Ridgway GL. Suction tip contamination in the ultraclean-air operating theatre. Ann R Coll Surg Engl. 1993;75:254-256.

12. Whyte W, Lidwell OM, Lowbury EJ, Blowers R. Suggested bacteriological standards for air in ultraclean operating rooms. $J$ Hosp Infect. 1983;4:133-139. doi:10.1016/0195-6701(83)90042-7

13. Durmaz G, Kiremitci A, Akgun Y, et al. [The relationship between airborne colonization and nosocomial infections in intensive care units]. Mikrobiyol Bul. 2005;39(4):465-471. Turkish.

14. Speaker MG, Milch FA, Shah MK, Eisner W, Kreiswirth BN. Role of external bacterial flora in the pathogenesis of acute postoperative endophthalmitis. Ophthalmology. 1991;98(5):639-649; discussion 650. doi:10.1016/S0161-6420(91)32239-5

15. Grzybowski A, Brona P, Kim SJ. Microbial flora and resistance in ophthalmology: a review. Graefes Arch Clin Exp Ophthalmol. 2017;255(5):851-862. doi:10.1007/s00417-017-3608-y

16. Tsui I. Scleral buckle removal: indications and outcomes. Surv Ophthalmol. 2012;57(3):253-263. doi:10.1016/j. survophthal.2011.11.001

17. Berkelman RL, Holland BW, Anderson RL. Increased bactericidal activity of dilute preparations of povidone-iodine solutions. $J$ Clin Microbiol. 1982;15(4):635-639. doi:10.1128/JCM.15.4.635639.1982

18. Roberts SM, Severin GA, Lavach JD. Antibacterial activity of dilute povidone-iodine solutions used for ocular surface disinfection in dogs. Am J Vet Res. 1986;47(6):1207-1210.

19. Ferguson AW, Scott JA, McGavigan J, et al. Comparison of $5 \%$ povidone-iodine solution against $1 \%$ povidone-iodine solution in preoperative cataract surgery antisepsis: a prospective randomised double blind study. $\mathrm{Br} \quad J$ Ophthalmol. 2003;87:163-167. doi:10.1136/bjo.87.2.163 
20. Papanikolaou T, Islam T, Hashim A, Mariatos G. Tolerability and safety profile of povidone iodine in pre-operative skin and eye disinfection prior to intraocular surgery. Clin Exp Ophthalmol. 2011;2:2.

21. Branemark P-I, Ekholm R, Albrektsson B, Lindström J, Lundborg G, Lundskog J. Tissue injury caused by wound disinfectants. J Bone Joint Surg Am. 1967;49(1):48-62. doi:10.2106/00004623196749010-00003

22. Zamora JL. Chemical and microbiologic characteristics and toxicity of povidone-iodine solutions. Am J Surg. 1986;151(3):400-406. doi:10.1016/0002-9610(86)90477-0
23. York KK, Miller S, Gaster RN, Burstein NL. Polyvinylpyrrolidone iodine: corneal toxicology and epithelial healing in a rabbit model. J Ocul Pharmacol. 1988;4(4):351-358. doi:10.1089/jop.1988.4.351

24. Wille H. Assessment of possible toxic effects of polyvinylpyrrolidone-iodine upon the human eye in conjunction with cataract extraction. An endothelial specular microscope study. Acta Ophthalmol. 1982;60:955-960. doi:10.1111/j.1755-3768.1982. tb00627.x

\section{Publish your work in this journal}

Clinical Ophthalmology is an international, peer-reviewed journal covering all subspecialties within ophthalmology. Key topics include: Optometry; Visual science; Pharmacology and drug therapy in eye diseases; Basic Sciences; Primary and Secondary eye care; Patient Safety and Quality of Care Improvements. This journal is indexed on PubMed

Submit your manuscript here: https://www.dovepress.com/clinical-ophthalmology-journal
Central and CAS, and is the official journal of The Society of Clinical Ophthalmology (SCO). The manuscript management system is completely online and includes a very quick and fair peer-review system, which is all easy to use. Visit http://www.dovepress.com/ testimonials.php to read real quotes from published authors. 